СОВЕРШЕНСТВОВАНИЕ ТУШЕНИЯ ПОЖАРА ЛЕГКОИСПАРЯЮЩИХСЯ ЖИДКОСТЕЙ

Шихамадов Ш.М., Адамян В.Л.

Донской Государственный технический университет, пл. Гагарина, 1.

В данной статье рассматриваются вопросы совершенствования тушения пожаров при разливе легковоспламеняющихся жидкостей в производственных помещениях при разгерметизации технологического оборудования. Обычно для ликвидации подобных пожаров основным средством тушения является пена средней (иногда низкой) кратности, тонко распыленная вода диссперсностью 0,10,5 мм, порошки для тушения небольших очагов. Рассматривается химический состав различных поверхностно-активны веществ (ПАВ), составляющих основу для приготовления пен различной кратности. Рассматривается возможность применения инертных газов при тушении пожара разлива в технологическом помещении, а также предлагается подслойное тушение ЛВЖ в резервуарах и емкостях. При подслойной подаче газа указывается на необходимость выбора тушащего газа с учетом разности плотностей вязкости ЛВЖ и тушашего газа. Для ЛВЖ с низкой плотностью, как, например, циановожород, предлагается тушение пожара самым легким инертным газом - гелием.

Ключевые слова: пожар, пена, порошки, подслойное тушение, легковоспламеняющиеся жидкости, инертный газ, гелий

\title{
IMPROVEMENT OF FIRE EXTINGUISHING IN CASE OF A SPILL VOLATILE LIQUIDS
}

Shikhamadov Sh.M., Adamyan L. V.

Don State technical University, Gagarin square, 1.

This article discusses the issues of improving fire fighting in the spill of flammable liquids in industrial premises during the depressurization of process equipment. Typically, to eliminate such fires, the main extinguishing agent is foam medium (sometimes low) multiplicity, finely atomized water dispersnosti 0.1-0.5 mm, powder to extinguish small fires. The chemical composition of various surfactants (surfactants), which form the basis for the preparation of foams of different multiplicity, is considered. The possibility of using inert gases to extinguish the fire of the spill in the process room is considered, and a sublayer extinguishing of LVH in tanks and containers is proposed. When subsurface gas flow indicates the need for selection of the quenching gas taking into account the density difference viscosity flammable liquids and extinguishing gas. For LVH with low density, such as cyanide, fire extinguishing is offered by the lightest inert gas - helium.

Keywords: fire, foam, powders, sub-layer extinguishing, flammable liquids, inert gas, helium

Для хранения легковоспламеняющихся жидкостей (ЛВЖ) самыми популярными считаются резервуары. Как правило, последние, в силу своих габаритов, размещаются в поднебесье. Однако, при проведении технологических процессов, особенно при пилотных исследованиях, во многих производствах промежуточные емкости могут располагаться в помещении. При этом аппараты постоянно или временно сообщаются с внешней средой через открытые люки, дыхательные линии, предохранительные клапаны или имеющие открытые поверхности испарения.

Наибольшую пожарную опасность для производства продуктов нефтехимии представляют собой нарушения режима работы технологического оборудования и связанные с ними повреждения и аварии, при которых за короткий промежуток времени может образоваться горючая концентрация не только внутри аппаратов, но и снаружи вследствие выхода значительного количества ЛВЖ. Для предотвращения образования паро- воздушногазовой смеси необходимо: 
- обеспечить полную герметизацию аппаратов, в которых хранится горючее вещество;

- поддерживать давление в аппаратах, равное проектному [1].

Горючая среда образуется в результате образования трещин, свищей, сквозных отверстий в емкостях, контактных аппаратах смесителях, теплообменниках. Количество паров жидкости, которое выходит из "дышащего" аппарата в атмосферное пространство, определяется по формуле

$$
G_{n}=\left(\frac{V_{1} \cdot\left(1-\varphi_{1}\right) \cdot P_{1}}{t_{1}+273}-\frac{V_{2} \cdot\left(1-\varphi_{2}\right) \cdot P_{2}}{t_{2}+273}\right) \cdot \frac{\varphi_{c p}}{1-\varphi_{c p}} \cdot \frac{M}{R}
$$

где $G_{n}$ - количество выходящих из резервуара паров нефтепродукта за один цикл "дыхания", кг/цикл;

$V_{1} u V_{2}$ - объем газового пространства соответственно в начале и конце "дыхания", м $^{3}$;

$P_{1} u P_{2}$ - атмосферное давление соответственно в начале и конце "дыхания", Па;

$\varphi_{1} u \varphi_{2}$ - концентрация насыщенных паров жидкости соответственно при температурах $t_{1}$ и $t_{2}$, об. доли;

$\varphi_{c p}$ - средняя концентрация насыщенного пара в резервуаре, об.доли:

$$
\varphi_{c p}=\frac{\varphi_{1}+\varphi_{2}}{2}
$$

$M$ - молекулярная масса жидкости, кг/кмоль;

$R=8314,31 \frac{\text { Дж }}{\text { кмоль } \cdot \text { К }}-$ универсальная газовая постоянная.

Одной из частых причин повреждения технологического оборудования является коррозия, которая может быть причиной его разгерметизации. Схема возможных сценариев развития аварийных ситуаций в цехе получения легкоиспаряющейся ЛВЖ с указанием основных причин их возникновения показана на рисунке 1.

Ликвидация пожаров легковоспламеняющихся жидкостей (ЛВЖ) осуществляется применением пенных стволов.

Пена на основе углеводородных ПАВ довольно быстро разрушается при контакте с поверхностью жидких углеводородов и при тепловом воздействии факела пламени [4]. Огнетушащая эффективность пены зависит от ее кратности и размера пузырьков. Наиболее эффективной на практике для поверхностного тушения является пена кратностью 100 и с размером пузырьков, по возможности, менее 1 мм. Чем меньше размер пузырька, тем выше эффективность, но для высокой кратности, например 150, эффективность существенно 

ветром.

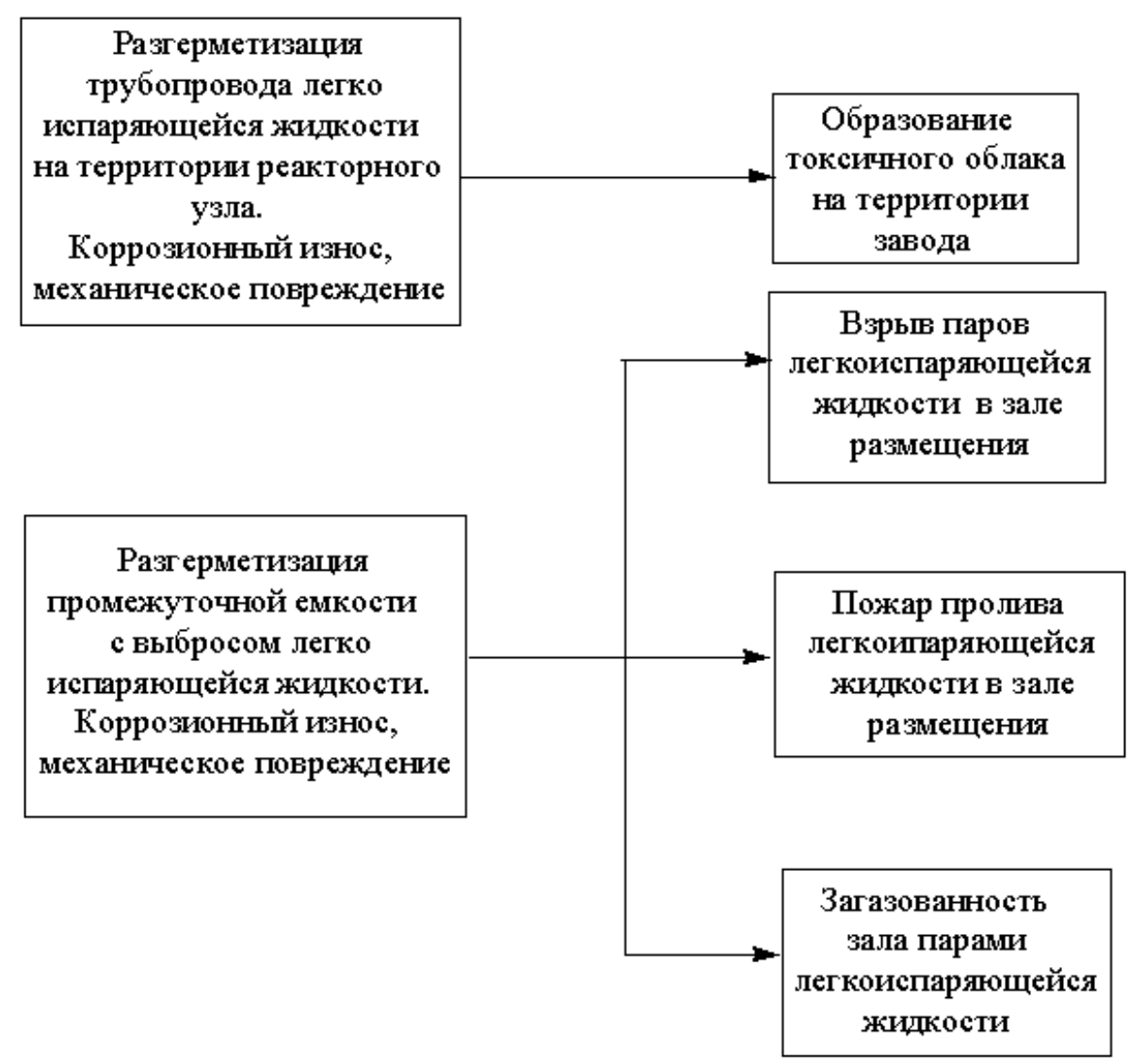

Рисунок 1. Схема возможных сценариев развития аварийных ситуаций в цехе получения легкоиспаряющейся жидкости с указанием основных причин их возникновения

ПАВы подразделяются на классы: неионогенные и анионные [1,2.4].

К неионогенным ПАВам относятся этоксилаты, пропоксилаты и бутоксилаты, синтезированные на основе взаимодействия высших жирных спиртов с оксидом этилена, оксидом пропилена и оксидом бутилена, соответственно:

$$
\begin{gathered}
\mathrm{R}-\mathrm{O}-\mathrm{H}+\mathrm{n} \mathrm{CH}_{2}-\mathrm{CH}_{2} \longrightarrow \mathrm{R}-\mathrm{O}-\left(\mathrm{CH}_{2}-\mathrm{CH}_{2}\right)_{-}-\mathrm{H} \\
\mathrm{R}-\mathrm{O}-\mathrm{H}+\mathrm{n}_{\mathrm{CH}}-\mathrm{CH}-\mathrm{CH}_{3} \longrightarrow \mathrm{R}-\mathrm{O}-\left(\mathrm{CH}_{2}-\mathrm{CH}-\mathrm{CH}_{3}\right)-\mathrm{H}
\end{gathered}
$$




$$
\mathrm{R}-\mathrm{O}-\mathrm{H}+\mathrm{n} \mathrm{CH}-\mathrm{CH}-\mathrm{CH}_{2}-\mathrm{CH}_{3} \longrightarrow \mathrm{R}-\mathrm{O}-\left(\mathrm{CH}_{2}-\mathrm{CH}-\mathrm{CH}_{2}-\mathrm{CH}_{3}\right)_{\mathrm{n}}-\mathrm{H}
$$

Реакции протекают в присутствии щёлочи при температуре до $160^{\circ} \mathrm{C}$ и давлении до 0,55МПа. Обычно используют $\mathrm{C}_{9}-\mathrm{C}_{15}$ спирты в сочетании с 6-7 молями эпоксидных соединений (оксидов этилена, пропилена или бутилена).

К неионогенным ПАВам относятся также алкилгликозиды, синтезируемые из высших спиртов и глюкозы:
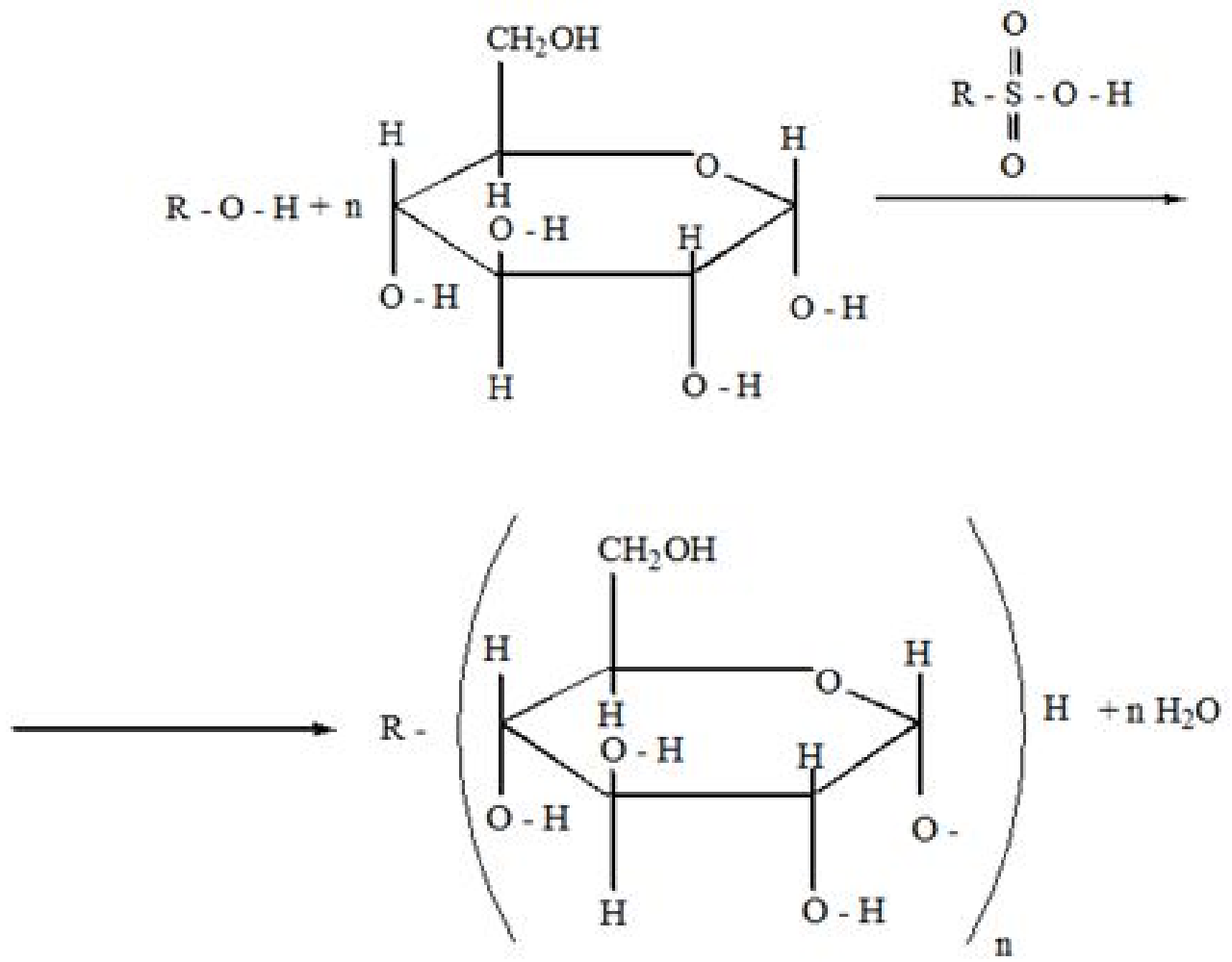

К анионным ПАВам относятся карбоксиэтоксилаты, фосфаты и полифосфаты, сульфосукцинаты, алкилсульфаты и алкилэфиросульфаты [2].

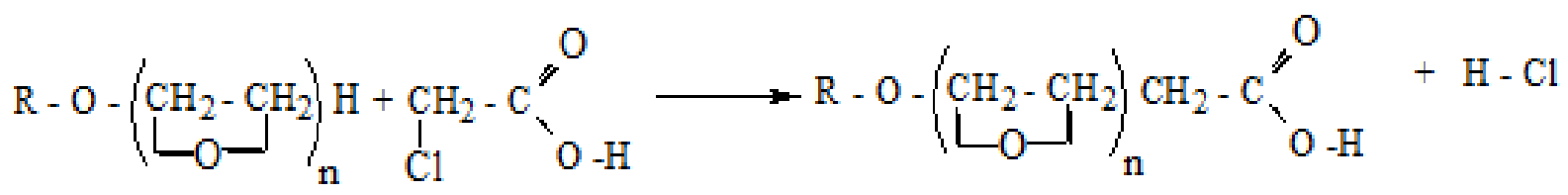

Карбоксиэтоксилаты получают синтезом этоксилата с хлоруксусной кислотой.

Реакция протекает в присутствии щёлочи, кислота выделяется подкислением водного раствора и отделением водно-солевой фазы.

Фосфаты и полифосфаты получают добавлением порошкообразного оксида фосфора к безводным спиртам в безводной среде при $50-70{ }^{\circ} \mathrm{C}$ и интенсивном перемешивании:

$$
3 \mathrm{R}-\mathrm{O}-\mathrm{H}+\mathrm{P}_{2} \mathrm{O}_{5} \longrightarrow \mathrm{ROP}(\mathrm{OH})_{2} \mathrm{O}+(\mathrm{RO})_{2} \mathrm{P}(\mathrm{OH}) \mathrm{O}
$$


Сульфосукцинаты получают этерификацией спиртов малиновым ангидридом при температуре до $100^{\circ} \mathrm{C}$ и дальнейшим присоединением к эфиру сульфита натрия при нагревании:<smiles>[R]OC=C[C@H](O)OC(=O)/C=C/C(=O)O[R]</smiles>

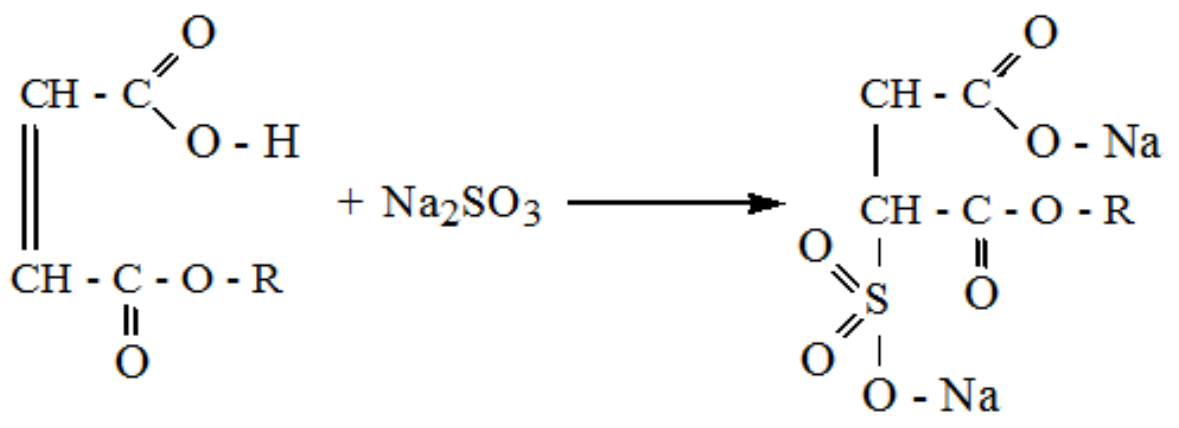

Алкилсульфаты являются продуктом прямого сульфирования спиртов при последующей нейтрализации раствора щелочью.

$$
\mathrm{R}-\mathrm{O}-\mathrm{H}+\mathrm{SO}_{3} \longrightarrow \mathrm{R}-\mathrm{O}-\mathrm{SO}_{3} \mathrm{H}
$$

Добавление в состав пенообразователя для тушения пожаров фторсинтетических ПАВ существенно увеличивает стойкость пены в зоне пожара. Однако стойкость пены не имеет никакого отношения к огнетушащей эффективности пены,

Помимо указанных веществ в состав пенообразователя могут входить, например, полисахариды. При тушении пеной водорастворимых (полярных) жидкостей, таких как спирты, эфиры, кислоты, ацетон , циановодорода и т.п. происходит взаимное растворение горящего вещества и водного раствора пенообразователя из которого состоит пена. Чтобы продлить «жизнь» пенного объема в зоне пожара в состав пенообразователя добавляются указанные вещества, которые полимеризуются и создают дополнительный каркас в пене.

Еще одна проблема - хранение пенообразователя в условиях низких температур решается добавлением в состав пенообразователя этиленгликоля. Растворение всех без исключения компонентов пенообразователя в этом веществе позволяет сохранить их в «жидком» состоянии даже при температурах минус $45^{\circ} \mathrm{C}$ или минус $60^{\circ} \mathrm{C}$. Качество пенообразователя, т.е. его огнетушащая эффективность существенно снижается, но, как утверждают некоторые специалисты, «находится в пределах требований ГОСТ Р». 
В связи с вышеописанным я предлагаю тушение пожара разлива ЛВЖ в помещениях инертным газом.

Установки тушения пожаров газовыми составами предназначены для тушения и локализации пожаров в тех случаях, когда применение других средств тушения не дает требуемого эффекта или ограничено какими-либо условиями [5]. В качестве средств тушения в этих установках используют двуокись, углерода, инертные газы (азот, аргон, гелий и др.) и легкоиспаряющиеся составы 3,5; 3,5в; Ж-Б (жидкостные - бромэтановые) и хладоны [3].

Огнегасительный состав «3,5», состоящий из 70\% бромистого этила и $30 \%$ углекислоты (по массе), предназначен для тушения легковоспламеняющихся и горючих жидкостей в помещениях и закрытых емкостях, а также разлитых на открытых площадках.

Из 1 кг состава «3,5» образуется 153 л углекислого газа (51,5\%' объемных) и 144 л паров бромистого этила (48,5\% объемных). Огнетушащая концентрация состава «3,5» в воздухе должна быть не более $7-8 \%$, так как по токсичности относится к наркотическим веществам, действие которых проявляется при концентрациях выше 7\% (по объему).

Все вышеописанное говорит в пользу использования в качестве огнетушащего вещества в закрытых помещениях инертные газы. При этом необходимо рассчитать объем инертного газа таким образом, чтобы концентрация кислорода в помещении понизилась до $15-17 \%$.

Для тушения пожара в закрытых емкостях можно предложить подслойную подачу инертного газа. При этом необходимо учитывать плотность и вязкость ЛВЖ и тушащего газа. Так, например, для тушения ацетона возможно применить азот, для циановодорода можно предложить только гелий.

Список использованной литературы:

1. Адамян В.Л. Физико-химические основы развития и тушения пожаров: Учебное пособие. СПб.: Издательство "Лань", 2018. - 176 с.

2. Бухштаб 3.И. Технология синтетических моющих веществ / З.И. Бухштаб, А.П. Мельник, В.М. Ковалев. - М.: Легпромбытиздат, 1988. - 320 с.

3. Молчадский И. С. Пожар в помещении. - М. : ВНИИПО, 2005. - 456 с.

4. Швырков С.А. Пожарная безопасность технологических процессов : учебник / С.А. Швырков и др. ; под общ. ред. С.А. Швыркова. - М.: Академия ГПС МЧС России, 2012. $388 \mathrm{c}$.

5. Драйздейл Д. Введение в динамику пожаров. / Пер. с англ. К.Г. Бомштейна; под ред.Ю.А. Кошмарова, В.Е. Макарова. - М.: Стройиздат, 1990. - 424 с. 